\title{
ALCOHOL USE IN CZECH PHARMACY STUDENTS
}

\author{
Alena Trojáčková1,2, Peter Višňovský1 \\ ${ }^{1}$ Faculty of Pharmacy in Hradec Králové, Charles University in Prague, Hradec Králové, Czech Republic \\ ${ }^{2}$ National Monitoring Centre for Drugs and Drug Addiction, Office of the Government of the Czech Republic, Prague, Czech Republic
}

\section{SUMMARY}

In academic years 2002/3-2004/5, the use of alcohol was investigated by anonymous questionnaire in 1,032 first and third year pharmacy students in the Czech Republic. Frequencies of beer, wine and spirits use, the age of the first contact with alcoholic beverages, the age of the first drunkenness and the frequency of drunkenness in the last month were ascertained. Average age of the first contact with alcoholic beverages was 12.9 years. $40.5 \%$ and $10.9 \%$ of students reported regular and hazardous drinking, respectively, with significantly higher proportion of men than women. Hazardous alcohol drinking significantly increased between academic years 2002/3 and 2004/5, no significant differences were found in the proportion of non-drinkers and regular alcohol drinkers over the 3-year-period of the survey. Both regular and hazardous drinking patterns were significantly related to the financial situation of the students. Significant associations were also found between alcohol consumption and using of both licit and illicit drugs of abuse.

Key words: alcohol, pharmacy students, regular drinking, hazardous drinking, Czech Republic

Address for correspondence: A. Trojáčková, Office of the Government of the Czech Republic, National Monitoring Centre for Drugs and Drug Addiction, Nábřeži Edvarda Beneše 4, 11801 Prague 1, Czech Republic. E-mail: trojackova.alena@vlada.cz

\section{INTRODUCTION}

The use of illicit drugs is a great social, health, economic, legal and politic problem both worldwide and in the Czech Republic. Alcohol together with tobacco belongs to the group of licit addictive substances. However, negative impacts of the consumption of alcohol on human health have been known for a long time. Alcohol is causally related to more than 60 different medical conditions and $4 \%$ of the global burden of disease is attributable to alcohol (1).

The attitudes of adult Czech population toward alcohol drinking may be characterised as tolerant or benevolent and the consumption of alcoholic beverages is high. In 2002, average statistical consumption of $100 \%$ spirit was 4 litres/year/person (including infants) in the Czech Republic (2). In the same year, $33 \%$ men and $14 \%$ women in the Czech Republic (age 18-64) consumed alcohol in a way hazardous for health, i.e. with a daily average $>40 \mathrm{~g}$ (men), $>20 \mathrm{~g}$ (women), or with periodic use of $\geq 75 \mathrm{~g}$ at a single occasion (3). Recently published data indicate slight decrease in alcohol consumption to 9.8 litres of $100 \%$ spirit/ year per capita in 2004 (4). However, the consumption of alcohol in the Czech Republic is still above the European average (5).

Such atmosphere leads to relatively high and hazardous alcohol consumption in the sample of adolescents. According to data from The European School Survey Project on Alcohol and Other Drugs 2003 (ESPAD), almost all students (age 16-17) in the Czech Republic had used alcohol during the last 12 months $(95 \%)$, which was higher than the European average (83\%) (6). Also, the proportion of students who were drunk during the last 12 months was higher (68\%) than the European average (53\%) (6). $17.5 \%$ and $13.3 \%$ of students (age 16-17) used excessive amount of alcohol (i.e. 5 or more glasses of alcoholic beverages at least three times per month) and were drunk at least three times during the last month, respectively (7). This is considered as hazardous drinking.

Most surveys on alcohol and other drug use have been restricted to elementary and secondary school students (e.g. ESPAD). However, research has revealed that some university students drink excessive amounts of alcohol. Alcohol abuse and dependence was identified in $14 \%$ of Belgium university students (8). $15 \%$ of drinking university students in the UK (9), ranging from $10 \%$ of veterinary, medical and mathematics/statistics students to $23 \%$ of biological science students (10), reported to drink alcohol at the hazardous level, i.e. over 50 and 35 units/week men and women, respectively. Heavy alcohol use (defined as typical use of $4 / 5$ or more drinks for women/men at a single occasion) was also found in US and Canadian students with prevalence rates $33 \%$ and $30 \%$, respectively (11). According to Kypri et al., the majority of drinking tertiary students in New Zealand ( $62 \%$ of men and $48 \%$ of women) reported hazardous or harmful alcohol use (12). Similar to other countries, the survey conducted in the population of Prague (capital city of the Czech Republic) university students revealed that $14 \%$ of students consumed alcohol in a hazardous way, i.e. they reported repeated drunkenness (more than 3 times a year) and their CAGE score was 2 or higher (13). However, the group of Czech pharmacy students was not included in this survey. For this reason, we explored if patterns of alcohol consumption of Czech pharmacy students are similar to those observed in other university students.

\section{METHODS}

The questionnaire-based survey was performed in academic years 2002/3-2004/5 at the Faculty of Pharmacy in Hradec Králové, Charles University in Prague, Czech Republic. Anony- 
mous standardized questionnaires were personally administered to the students during their registration at the beginning of the academic years and almost all students participated.

The questionnaire included questions on the use of alcohol, tobacco and illicit drugs of abuse, general socio-demographic data (e.g. age, sex, residence, education of parents, financial means, home circumstances), knowledge and attitudes of students towards drugs of abuse.

For the assessment of alcohol intake, students were asked about frequencies of beer, wine and spirits use, the age of the first contact with alcoholic beverages, the age of the first drunkenness and the frequency of drunkenness in the last month. The consumption of any sort of alcoholic beverage at least once a week was stated as the indicator of regular alcohol consumption. Repeated drunkenness (i.e. at least two or three episodes of drunkenness per month) was used as the indicator of hazardous alcohol drinking.

The results are presented as descriptive statistics. Associations between variables were analysed by $\chi^{2}$ test.

\section{RESULTS}

\section{Characteristics of the group}

A total number of 1,032 students completed and returned the distributed questionnaires, of them 679 were first year and 353 third year pharmacy students. The average age of students was 20.2 years (range: 18-34), 19.6 and 21.5 years in first and third year students, respectively. The number of women was higher $(83.3 \%)$ than that of men (16.6\%) (Table 1).

\section{Alcohol drinking}

$6.1 \%$ of students ( $5.0 \%$ of men, $6.3 \%$ of women) in academic year $2002 / 3,5.9 \%(4.6 \%, 6.2 \%)$ in $2003 / 4$ and $3.0 \%(3.0 \%$, $3.0 \%$ ) in 2004/5 did not drink (Fig. 1). During the 3-year period of the survey, no significant differences in the proportion of nondrinkers were found.

$40.5 \%$ of students reported regular consumption of any sort of alcoholic beverage (i.e. consumption at least once a week). Proportion of regular drinkers increased from $36.8 \%$ in academic year $2002 / 3$ to $41.3 \%$ in $2003 / 4$ and $42.0 \%$ in $2004 / 5$ (Fig. 1). On average, $26.5 \%, 22.1 \%$ and $6.2 \%$ of students reported regular consumption of beer, wine and spirits, respectively. Regular consumption of beer and spirits increased over the 3-year period of the survey, regular consumption of wine was relatively stable.

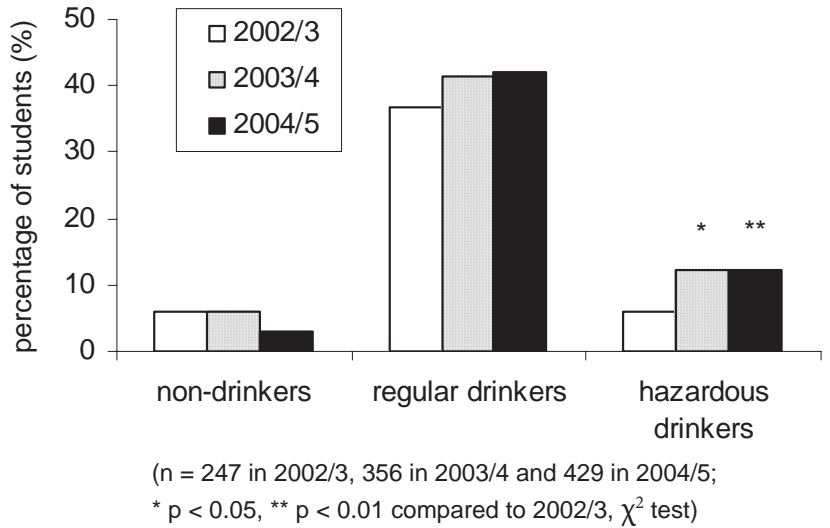

Fig.1. Prevalence of non-drinking, regular and hazardous drinking of alcohol in pharmacy students.

Hazardous alcohol drinking (i.e. at least two or three episodes of drunkenness per month) was reported by $6.1 \%$ of students in academic year 2002/3, 12.4\% in both 2003/4 and 2004/5 (Fig. 1). Decreasing trend was found in the proportion of students who had never been drunk $-29.1 \%$ of students in academic year 2002/3 and $20.5 \%$ in $2004 / 5$.

Average age of the first contact with alcoholic beverages and average age of the first drunkenness were relatively stable during the 3-year-period of the survey; 12.9 years (range: 2-22) and 16.4 years (range: $5-22$ ), respectively. More than $55 \%$ of students reported being drunk for the first time before the age of 18 (licit age limit of alcohol consumption in the Czech Republic).

\section{Sex differences}

When comparing alcohol consumption of men and women, several differences were observed. More women (4.9\%) than men (4.1\%) did not drink alcohol. Both regular and hazardous alcohol consumption was reported by significantly more men than women (63.2\% vs. $36.0 \%$ and $22.8 \%$ vs. $8.5 \%$, respectively) (Fig. 2).

There were sex differences in the consumption of individual alcoholic beverages with $59.6 \%$ and $13.5 \%$ of men being regular drinkers of beer and spirits compared to $19.9 \%$ and $4.8 \%$ of women, respectively. Both regular consumption of wine and the age of the onset of alcohol drinking did not differ comparing men and women. However, significantly higher proportion of men $(69.0 \%)$ than women $(53.0 \%)$ reported their first drunkenness before the age of $18\left(\mathrm{p}<0.001, \chi^{2}\right.$ test $)$.

Table 1. Demographic characteristics of pharmacy students

\begin{tabular}{|c|c|c|c|c|c|c|c|c|}
\hline \multirow{2}{*}{ Academic year } & \multirow{2}{*}{ Year of study } & \multicolumn{2}{|c|}{ Men } & \multicolumn{2}{|c|}{ Women } & \multirow{2}{*}{$\begin{array}{c}\text { Sex not } \\
\text { stated }\end{array}$} & \multirow{2}{*}{$\begin{array}{c}\text { Total num- } \\
\text { ber }\end{array}$} & \multirow{2}{*}{ Average age } \\
\hline & & $\mathrm{n}$ & $\%$ & $\mathrm{n}$ & $\%$ & & & \\
\hline \multirow{2}{*}{$2002 / 3$} & first-year & 23 & 13.6 & 146 & 86.4 & 0 & 169 & 19.6 \\
\hline & third-year & 17 & 21.8 & 61 & 78.2 & 0 & 78 & 21.3 \\
\hline \multirow{2}{*}{$2003 / 4$} & first-year & 43 & 16.7 & 215 & 83.3 & 0 & 258 & 19.6 \\
\hline & third-year & 22 & 22.4 & 76 & 77.6 & 0 & 98 & 21.5 \\
\hline \multirow{2}{*}{$2004 / 5$} & first-year & 30 & 11.9 & 221 & 87.7 & 1 & 252 & 19.6 \\
\hline & third-year & 36 & 20.3 & 141 & 79.7 & 0 & 177 & 21.5 \\
\hline
\end{tabular}

$\mathrm{n}=$ number, $\%$ = percentage 


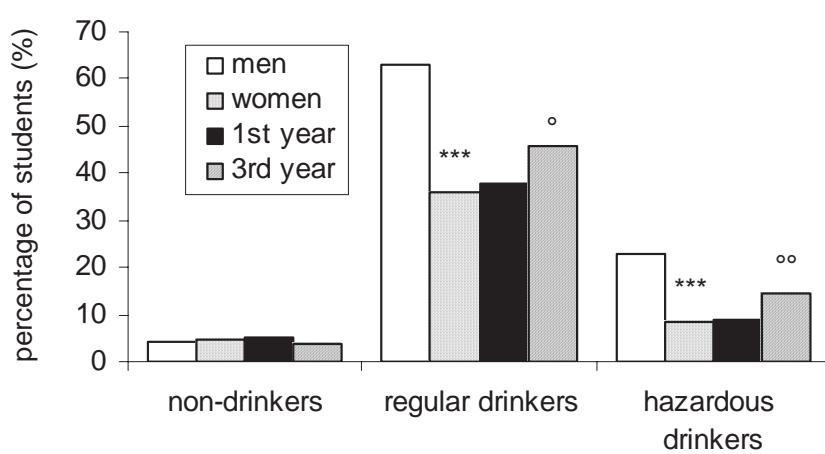

(number of men $=171$, number of women $=860$, number of $1^{\text {st }}$ year students $=679$, number of $3^{\text {rd }}$ year students $=353 ;{ }^{* \star *} \mathrm{p}<0.001$ compared to men ${ }^{\circ} p<0.05$ and ${ }^{\circ} p<0.01$ compared to $1^{\text {st }}$ year students, $\chi^{2}$ test)

Fig. 2. Prevalence of non-drinking, regular and hazardous drinking of alcohol in men and women, $1^{\text {st }}$ and $3^{\text {rd }}$ year students.

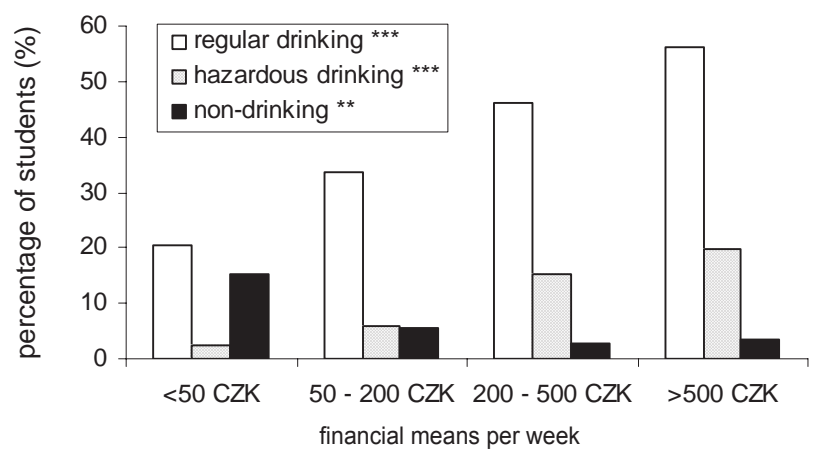

(CZK = Czech Crown; ${ }^{* *} p<0.01,{ }^{* * *} \mathrm{p}<0.001$ financial means compared to alcohol drinking, $\chi^{2}$ test).

Fig. 3. Association between the financial means and the prevalence rates of non-drinking, regular and hazardous drinking of alcohol.

\section{Grade differences}

$4.0 \%$ of $1^{\text {st }}$ year and $5.2 \%$ of $3^{\text {rd }}$ year students did not drink (Fig. 2). Both regular and hazardous alcohol consumption was reported by significantly more $3^{\text {rd }}$ year than $1^{\text {st }}$ year students (45.6\% vs. $38.0 \%$ and $14.4 \%$ vs. $9.0 \%$, respectively) (Fig. 2).

Significant differences were found in regular consumption of beer and spirits with $21.5 \%$ and $4.6 \%$ of $1^{\text {st }}$ year students being regular drinkers of beer and spirits compared to $36.0 \%$ and $9.3 \%$ of $3^{\text {rd }}$ year students, respectively $(\mathrm{p}<0.001$ beer, $\mathrm{p}<0.01$ spirits; $\chi^{2}$ test). Regular consumption of wine did not differ comparing $1^{\text {st }}$ and $3^{\text {rd }}$ year students.

Significantly more $1^{\text {st }}$ year students than $3^{\text {rd }}$ year students reported being drunk for the first time before the age of 18 (58.5\% vs. $50.4 \%, p<0.05, \chi^{2}$ test). Both average age of the first contact with alcoholic beverages and average age of the first drunkenness did not differ comparing $1^{\text {st }}$ and $3^{\text {rd }}$ year students.

\section{Associations}

There was a statistically significant association between the financial situation of students (i.e. financial means per week) and use of alcohol beverages. Higher amount of financial means per week was related to the increasing proportion of regular and

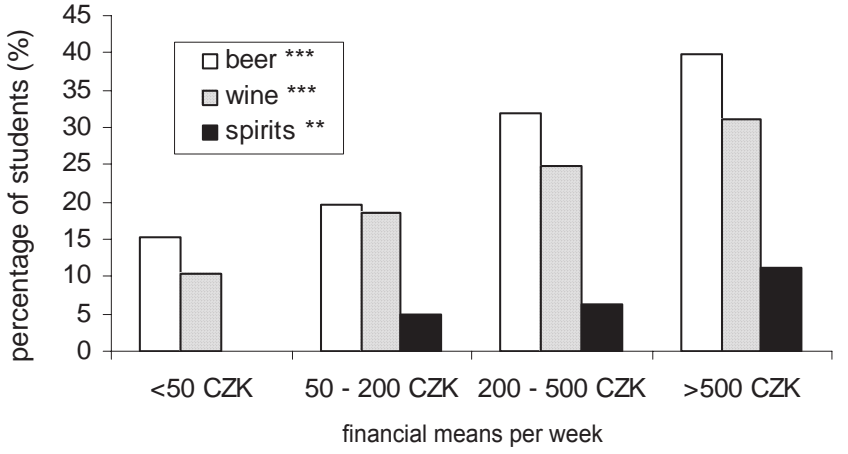

(CZK = Czech Crown; ${ }^{* *} \mathrm{p}<0.001,{ }^{* *} \mathrm{p}<0.01$ financial means compared to drinking of alcohol beverages, $\chi^{2}$ test)

Fig. 4. Association between the financial means and the prevalence rates of beer, wine and spirits regular drinking.

hazardous drinking (Fig. 3) as well as regular drinking of beer, wine and spirits (Fig. 4).

Alcohol consumption was also significantly related to both tobacco smoking and the use of illicit drugs of abuse (Table 2). Regular smokers and students who had tried illicit drugs reported regular and hazardous drinking more frequently than non-smokers and students who were not taking other drugs of abuse.

\section{DISCUSSION}

Pharmacy students as other healthcare students are considered the youngest members of the society active in the education and

Table 2. Relationship between alcohol consumption and tobacco smoking, use of illicit drugs of abuse, and financial means per week

\begin{tabular}{|l|c|c|c|}
\hline \multicolumn{1}{|c|}{ Tobacco smoking } & $\begin{array}{c}\text { Non-drin- } \\
\text { king (\%) }\end{array}$ & $\begin{array}{c}\text { Regular } \\
\text { drinking } \\
(\%) * * *\end{array}$ & $\begin{array}{c}\text { Hazardous } \\
\text { drinking } \\
(\%) * * *\end{array}$ \\
\hline Never $(n=707)$ & 6.8 & 30.1 & 5.2 \\
\hline Ex-smoker $(n=59)$ & 0.0 & 59.3 & 15.3 \\
\hline Irregular smoker $(n=205)$ & 0.0 & 61.5 & 20.0 \\
\hline Regular smoker $(n=61)$ & 1.6 & 72.1 & 41.0 \\
\hline Illicit drug use & \multicolumn{4}{|l}{} \\
\hline Never $(n=551)$ & 7.8 & 25.8 & 3.4 \\
\hline Once $(n=147)$ & 1.4 & 32.7 & 4.8 \\
\hline$>$ Once $(n=332)$ & 1.2 & 68.1 & 25.6 \\
\hline Financial means per week & \multicolumn{3}{|l}{} \\
\hline$<50$ CZK $(n=39)$ & 15.4 & 20.5 & 2.6 \\
\hline $50-200$ CZK $(n=516)$ & 5.6 & 33.5 & 5.8 \\
\hline $200-500$ CZK $(n=301)$ & 2.7 & 46.2 & 15.3 \\
\hline$>500$ CZK $(n=171)$ & 3.5 & 56.1 & 19.9 \\
\hline
\end{tabular}

${ }^{* *} \mathrm{p}<0.01,{ }^{* *} \mathrm{p}<0.001, x^{2}$ test, $\mathrm{n}=$ number, $\%=$ percentage 
the propagation of healthy lifestyle. In their future occupations, their knowledge and attitudes to alcohol and to other drugs of abuse might help to extend the prevention and the treatment of hazardous and regular licit and illicit drug use and may affect any future evaluation of these drugs of abuse. However, this study of a group of pharmacy students revealed that many of them drink alcohol regularly or in a way hazardous for health. Moreover, regular and hazardous drinking patterns were reported by higher proportion of third year than first year students, which might show unsatisfactory educational programs in the field of licit and illicit drug addiction at the Faculty of Pharmacy.

$40.5 \%$ and $10.9 \%$ of pharmacy students reported regular and hazardous alcohol drinking, respectively. High alcohol consumption was also found in other university students both in the Czech Republic $(13,14)$ and worldwide (e.g. 8-12). However, adequate comparison of our findings with those from other studies is problematic mainly because of different measures of alcohol intake, different definitions of hazardous alcohol drinking, differences in the age distribution across samples and different licit age limits of alcohol drinking. Since such limitations exist, we compare our data mainly with results of Czech surveys with maximal similarity at least in their milieu.

Comparison of our results to findings of the survey conducted in Prague university students in 2004 (13) revealed that both regular alcohol consumption and repeated drunkenness [defined by Csemy et al. as more than three drunkenness per year (13)] were higher in Prague students (52.0 and 27.4\%, respectively). Similarly, higher proportion of Prague university students reported regular drinking of beer, wine and spirits $-39.9 \%, 23.4 \%$ and $9.2 \%$, respectively.

Hazardous drinking in pharmacy students significantly increased between years 2002/3 and 2003/4, no significant differences were found in the proportion of non-drinkers and regular alcohol drinkers over the 3-year-period of the survey. When compared with previous results in pharmacy students, however, significant decrease in the proportion of non-drinkers $(8.7 \%$ in academic year $2000 / 1$ vs. $3.0 \%$ in $2004 / 5$; p $<0.01, \chi^{2}$ test) was noted (14).

We found sex differences in alcohol consumption, both regular and hazardous drinking patterns were reported by higher proportion of men than women. Also regular consumption of beer and spirits was significantly higher in men. First year students had some experience with alcohol drinking before starting university, however, we found higher proportion of regular and hazardous drinking in third year students. Such findings (sex and grade differences) are consistent with earlier reports on alcohol and drug use in other university students (e.g. 9, 10, 13, 15, 16, 17).

A significant positive association between alcohol consumption and financial situation of students was found. Students with greater financial support drank alcohol more often and they reported drunkenness more frequently. These findings corroborates earlier results in Czech university students $(14,18)$.

A link between alcohol consumption and use of other drugs of abuse (licit or illicit) was found. This finding confirms results of earlier studies on alcohol and drug use (e.g. 15, 19) and can support the theory that alcohol could act as a 'gateway' to the use of illicit drugs (15).

According to the results of the population survey conducted in the Czech Republic in 2002 (3), hazardous drinking was reported by similar proportion of pharmacy students' peers (age 18-24) in general population ( $8.5 \%$ vs. $11.1 \%$ of women and $22.8 \%$ vs. $16.3 \%$ of men). Moreover, the highest rate of hazardous alcohol consumption in general population was found in the group of 35 -44 years old adults with $33 \%$ of men and $13 \%$ of women (3). This is in accordance with results of the longitudinal survey conducted in a cohort of medical students during their undergraduate studies and as qualified doctors in the UK, which had showed a significant increase in the consumption of both alcohol and illicit drugs during the period of the survey (16). Therefore, it would be important to establish whether Czech pharmacy students change their drinking patterns after becoming healthcare professionals.

The reliability and accuracy of the data can be subjected to discussion. We suppose that voluntary, anonymous and confidential principle of our survey improved reliability of students' responses. Furthermore, questionnaires were personally administered to the students during their registration at the beginning of the academic years (with obligatory participation of students) and completed by almost all students.

\section{CONCLUSIONS}

Hazardous alcohol drinking is strongly associated with a range of negative health and psychological consequences (1). Healthcare professionals should help in the treatment of such alcohol abuse. However, our study among pharmacy students in the Czech Republic, as future healthcare professionals, provides worrying data about their consumption of alcohol and supports the need of continuous education also in university students to advise them on the risks of alcohol misuse.

\section{Acknowledgement}

This study was supported by grant MSM111600004.

\section{REFERENCES}

1. Room R, Babor T, Rehm J. Alcohol and public health. Lancet 2005 Feb 5-11;365(9458):519-30.

2. Csémy L, Sovinová H. Consumption of alcohol in the Czech Republic. In: Sovinová H, Csémy L, editors. Smoking of cigarettes and drinking of alcohol in the Czech Republic. Prague: The National Institute of Public Health; 2003. p. 34-47. (In Czech.)

3. Kubička L, Csémy L. An analysis of the sociodemographic context of alcohol use in the Czech adult population from the health perspective. Cas Lek Ces. 2004; 143(7):435-9. (In Czech.)

4. Czech Statistical Office. Food consumption in 2004 [mongraph on the Internet]. Prague: Czech Statistical Office; c2006 [cited 2006 Apr 20]. Available from: http://www.czso.cz/eng/edicniplan.nsf/p/3004-05.

5. Alcohol control database [database on the Internet]. Copenhagen: World Health Organization Regional Office for Europe; c2006 [cited 2006 Apr 20]. Available from: http://data.euro.who.int/alcohol.

6. The European school survey project on alcohol and other drugs. Key results The Czech Republic [homepage on the Internet]. Stockholm: The Swedish Council for Information on Alcohol and Other Drugs (CAN), The Pompidou Group at the Council of Europe [cited 2005 Jun 23]. Available from: http://www.espad.org/key_czech.html.

7. Csémy L, Lejčková P, Sadílek P, Sovinová H. The European school survey project on alcohol and other drugs (ESPAD): results for the Czech Republic 2003. Prague: Office of the Government of the Czech Republic. In press. (In Czech.)

8. Aertgeerts B, Buntinx F. The relation between alcohol abuse or dependence and academic performance in first-year college students. J Adolesc Health. 2002 Sep;31(3):223-5. 
9. Webb E, Ashton CH, Kelly P, Kamali F. Alcohol and drug use in UK university students. Lancet. 1996 Oct 5;348(9032):922-5.

10. Webb E, Ashton H, Kelly P, Kamali F. Patterns of alcohol consumption, smoking and illicit drug use in British university students: interfaculty comparisons. Drug Alcohol Depend.1997 Aug 25;47(2):145-53.

11. Kuo M,AdlafEM, Lee H, Gliksman L, Demers A, Wechsler H. More Canadian students drink but American students drink more: comparing college alcohol use in two countries. Addiction. 2002 Dec;97(12):1583-92.

12. Kypri K, Langley JD, McGee R, Saunders JB, Williams S. High prevalence, persistent hazardous drinking among New Zealand tertiary students. Alcohol Alcohol. 2002 Sep-Oct;37(5):457-64.

13. Csémy L, Hrachovinová T, Krch DF. Alcohol consumption and illici substance use in Prague university students. Adiktologie. 2004;2:152-35. (In Czech.)

14. Syrovcová L, Venderová K, Višňovský P. Attitudes of undergraduate pharmacy students towards alcohol and smoking. Folia Pharm Univ Carol. 2001;26:75-82.
15. Newbury-Birch D, White M, Kamali F. Factors influencing alcohol and illicit drug use amongst medical students. Drug Alcohol Depend. 2000 May 1;59(2):125-30.

16. Newbury-Birch D, Walshaw D, Kamali F. Drink and drugs: from medical students to doctors. Drug Alcohol Depend. 2001 Nov 1;64(3):265-70.

17. Pickard M, Bates L, Dorian M, Greig H, Saint D. Alcohol and drug use in second-year medical students at the University of Leeds. Med Educ. $2000 \mathrm{Feb} ; 34(2): 148-50$

18. Beckova I, Visnovsky P. Drug use in the Czech Republic university students. FABAD J Pharm Sci. 2000;25(2):41-4.

19. Webb E, Ashton H, Kelly P, Kamali F. An update on British medical students’ lifestyles. Med Educ.1998 May;32(3):325-31.

Received February 20, 2006 Received in revised form and accepted April 24, 2006 